\title{
Mujeres prostituidas y trabajadoras sexuales: ¡̨es el derecho del trabajo una vía para superar la condición de vulnerabilidad?
}

\author{
Prostituted women and sex female workers: is the Labour Law \\ a way to overcome the status of vulnerability?
}

\author{
Adoración Guamán Hernández \\ Universidad de Valencia \\ ORCID ID: 0000-0002-7405-7478
}

doi: https://doi.org/10.20318/labos.2020.5545

Resumen: $\quad$ El presente texto aborda un tema tan complicado como la prostitución desde la perspectiva de la política del derecho y sin ahondar en la dicotomía existente entre el abolicionismo y el movimiento pro-derechos. Al contrario, en el artículo se plantea un enfoque alternativo que ponga la dignidad y la voluntad de los sujetos en el centro y de manera conjunta, situándose en un espacio intermedio y apostando por la necesidad de establecer un diálogo sobre la base de dos premisas: la aspiración de la desaparición de la prostitución como meta final y el reconocimiento de derechos a las personas que deciden prostituirse, sin que eso implique un uso impropio, y poco efectivo, del derecho del trabajo. En cambio, se plantean otras alternativas para, en el momento presente, dotar de herramientas que permitan una salida de la vulnerabilidad a través del reconocimiento de derechos.

Palabras clave: vulnerabilidad, reconocimiento, prostitución, derechos laborales.

Abstract: $\quad$ The present text addresses a topic as complicated as prostitution from the perspective of the politics of law and without delving into the dichotomy between abolitionism and the pro-rights movement. On the contrary, in the article an alternative approach is proposed that puts the dignity and will of the subjects at the center and together, placing itself in an intermediate space and betting on the need to establish a dialogue based on two premises: the aspiration of the disappearance of prostitution as an end goal and the recognition of rights to people who decide to prostitute themselves, without implying an improper and ineffective use of labor law. Instead, other alternatives are proposed to, at the present time, provide tools that allow an exit from vulnerability through the recognition of rights.

Keywords: vulnerability, recognition, prostitution, labor rights. 


\section{Introducción}

Desde el paradigma de la ciencia crítica es imposible escribir sin tomar partido. No existe, y menos en un tema como la prostitución, un espacio que permita una utilización aparentemente neutra del Derecho y que, bajo el manto de una supuesta objetividad científica, permita un diseño de laboratorio de una propuesta normativa no situada. De hecho, ningún análisis jurídico de la realidad debería realizarse de manera despegada del contexto material y de las condiciones subjetivas que se ven o verían afectadas por los instrumentos normativos criticados o propuestos. Si esta aserción es válida para el conjunto de la ciencia jurídica, lo es mucho más respecto de los análisis que se enfocan en los usos del derecho del trabajo.

El presente texto parte de estas premisas para adentrarse en la compleja cuestión de la prostitución. Al abordar un tema tan complicado como discutido y revisado, en particular en los últimos tiempos, las siguientes páginas no pretenden ahondar en la dicotomía existente entre las bien conocidas posiciones enfrentadas, como son el abolicionismo y el movimiento pro-derechos ${ }^{1}$. Al contrario, se plantea un enfoque alternativo que ponga la dignidad y la voluntad de los sujetos en el centro y de manera conjunta, situándose en un espacio intermedio y apostando por la necesidad de diálogo sobre la base de dos premisas: la aspiración de la desaparición de la prostitución como meta final y el reconocimiento de derechos a las personas que deciden prostituirse, sin que eso implique un uso impropio, y poco efectivo, del derecho del trabajo.

\section{Prostitución, vulnerabilidad y usos del derecho del trabajo}

A efectos del análisis que se aborda en el presente texto, entenderemos por prostitución el intercambio de sexo a cambio de una contraprestación económica, realizado entre adultos y sin coacción directa de otra persona o personas². Queda pues fuera de la realidad que aquí se estudia todo el amplio panorama vinculado a la trata y las situaciones de esclavitud moderna ${ }^{3}$.

\footnotetext{
${ }^{1}$ Son muchos los estudios que detallan los modelos que se ocupan de enfocar normativamente los intercambios sexuales retribuidos, que pueden resumirse en los cuatro fundamentales: reglamentista, prohibicionista, abolicionista y regulador. Sin embargo, entre o sobre estos modelos se articulan otros, en torno a los cuales tratarán las conclusiones del presente texto. Sobre esta cuestión hay una ingente literatura, se remite por ejemplo a GAY Silvia., OTAZO E., SANZ M., "¿Prostitución=profesión? Una relación a debate”, Aequalitas. Revista Juridica de Igualdad de Oportunidades entre Mujeres y Hombres, nº. 13, julio-diciembre 2003; HEIM, Daniela. "Prostitución y Derechos Humanos", Cuadernos Electrónicos de Filosofía del Derecho, No23, 2011.

${ }^{2}$ Siendo esta una definición estándar que permite el razonamiento jurídico típico, es importante incidir en la existencia de otras definiciones "situadas" que persiguen un abordaje mucho más amplio y pluridisciplinar del fenómeno. Así, la feminista Beatriz Gimeno pone el énfasis en la prostitución como un privilegio masculino con inmensa capacidad para construir tanto subjetividad como engranaje simbólico, sobre el que además la construcción de espacios de combate unánimes se revela muy difícil. Desde este prisma, la autora lanza la siguiente definición: "Prostitución: Institución patriarcal que busca garantizar a todos los varones la posibilidad de acceso a tantos cuerpos de mujeres quieran. Para ello, el patriarcado debe garantizar, por medio de la desigualdad estructural, por medio de la ideología sexual patriarcal y de toda una estructura simbólica y cultural, que siempre habrá un contingente de mujeres dispuestas a ocupar ese espacio previamente señalado para las mujeres públicas". Vid. GIMENO, Beatriz, "Prostitución: cuestión de derechos y privilegios", en Ctxt, № 239, 2019. Disponible en: https://ctxt.es/es/20190918/Firmas/28489/prostitucion-institucionpatriarcal-desigualdad-beatriz-gimeno.htm

${ }^{3}$ Según la estimación mundial sobre la esclavitud moderna se estima que en cualquier momento dado de 2016, existían 40.3 millones de personas en esta situación. El término "esclavitud moderna" incluye las categorías de trabajo forzoso, el matrimonio forzado y la trata, teniendo los tres ejes evidentes conexiones. Según la cifras del "Global Slavery Index", publicado en 2017, dentro del conjunto de esclavas/os, 15.4 millones de mujeres se encuentran bajo matrimonio forzoso y 24,9 millones de personas están sometidas al trabajo forzoso. De ellas, 16 millones son explotadas en el sector privado, por ejemplo, en el trabajo doméstico, la industria de la construcción, la agricultura y el textil; 4 millones de personas se encuentran en situación de trabajo forzoso impuesto por el Estado y 4,8 millones de personas son víctimas de la explotación sexual forzosa. El trabajo forzoso afecta en forma desproporcionada a las mujeres y nińas, que representan el 99 por ciento de las víctimas en la industria sexual comercial y el 58 por ciento en otros sectores, Vid. Organización Internacional del Trabajo (OIT) y Walk Free Foundation, Global Estimates of Modern Slavery: Forced Labour and Forced Marriage, Ginebra, 2017.
} 
Dentro de estos márgenes, entendidos de manera estricta porque no hay otra manera de abordar el fenómeno que el establecimiento de tabiques para diferenciar plenamente la lucha efectiva contra la esclavitud sexual, el estudio de la situación se va a abordar desde el prisma crítico antedicho y desde la noción-instrumento de "vulnerabilidad". Entenderemos este concepto apartándonos de un uso tradicional del mismo, que se ocupa de delinear las características de los grupos vulnerables para diferenciarlos de los otros y convertirlos en objeto de políticas públicas. En cambio, nuestra aproximación al contexto se realizará por el camino del estudio multidimensional de las causas de vulnerabilidad y del papel que los derechos, y en particular el ordenamiento laboral, pueden asumir en la superación de las mismas, atendiendo a las personas implicadas como sujetos protagonistas en el diseño de las vías de superación.

Entendemos por tanto, de manera básica, la vulnerabilidad como la condición de indefensión de determinados grupos sociales frente a determinados riesgos o determinadas dinámicas sociales que los vulnerabilizan ${ }^{4}$, incluyendo en esta condición el impacto de la carencia de la cobertura de los sistemas, instituciones y redes que la sociedad facilita a otros grupos no (igualmente) expuestos. En palabras de Martínez de Bringas, es necesario asumir la vulnerabilidad como "principio de reconocimiento del valor de la persona" para poder impulsar el verdadero papel y función de los derechos humanos en general y muy concretamente los sociales 5 .

Asumir la igualdad real como punto de llegada implica admitir un concepto de vulnerabilidad amplio cuya atención requiere una actuación conjunta desde diversos planos. En este sentido, y siguiendo el análisis del autor mencionado, debe tenerse presente que la superación de la vulnerabilidad no depende de un solo eje. Así, por ejemplo, la integración laboral es, con carácter general, solo una de las vías de salida de la vulnerabilidad que debe cohonestarse necesariamente con el acceso a recursos materiales, pero también con la autonomía funcional y la integración relacional en redes sociales, familiares y comunitarias. De hecho, cabe recordar que la vinculación de la condición de ciudadanía y los derechos a ella anudados con el empleo formal, típica en nuestro modelo de Estado Social, deja de ser asumible con la ruptura del pacto social y la degradación tanto del poder del sujeto trabajo como del conjunto de los derechos laborales.

En un modelo donde la inserción en una relación de empleo formal deja de ser una garantía de no-vulnerabilidad económico-social, el vínculo laboral solo puede ser uno, y no el más importante, de los puntos de lucha por el goce efectivo de los derechos sociales como puerta hacia la superación de la vulnerabilidad.

Enfocar el complejo binomio "prostitución-Derecho" desde esta base implica encauzar la discusión respeto de la acción jurídica deseable poniendo el acento en la utilidad de los instrumentos normativos que deben diseñarse para superar la situación de vulnerabilidad de las personas cuyos ingresos se derivan del ejercicio de la prostitución.

\subsection{Vulnerabilidad y prostitución como causa y consecuencia}

En la realidad que estudiamos es posible determinar dos causas de vulnerabilidad entrecruzadas. En primer lugar, el género, entendiendo que la habitual situación de desventaja de la mujer en los ámbitos público y privado la coloca en una posición vulnerable derivada de las estructuras patriarcales, religiosas o tradicionales que actúan de manera mutilante, proyectándose en el plano económico, en

\footnotetext{
${ }^{4}$ MORONDO TARAMUNID, Dolores, “¿Un nuevo paradigma para la igualdad? La vulnerabilidad entre condición humana y situación de indefensión” en Cuadernos Electrónicos de Filosofía del Derecho. No34, 2016.

${ }^{5}$ MARTÍNEZ DE BRINGAS, Asier, "Los derechos sociales ante la vulnerabilidad. Retos y problemáticas en un marco de flexibilidad y desregulación”, R.V.A.P. núm. 111. Mayo-Agosto 2018.
} 
el ámbito del trabajo (reproductivo y no reproductivo) y en la esfera política ${ }^{6}$. La carencia económica, la informalidad y precariedad laboral, la ausencia de trabajo remunerado y el déficit de políticas orientadas a atajar este conjunto de circunstancias son factores que inciden en la capacidad de las mujeres de determinar con libertad su modo de vida, incluyendo su manera de percibir ingresos para subsistir. Evidentemente, una mayor situación de vulnerabilidad reduce las posibilidades de decisión y limita esa libertad, abocando a un conjunto de decisiones sobre la supervivencia que, muy posiblemente, con otras condiciones de partida serían distintas.

El ejercicio de la prostitución, prostituirse como única, más cercana o más eficaz opción para sobrevivir, podría considerarse como una decisión derivada de condiciones materiales y simbólicas que limitan las posibilidades de tener o plantearse otra realidad ${ }^{7}$. Encontraríamos así que la vulnerabilidad de género se sitúa en la base de otra serie de vulnerabilidades, entre las que se encuadra la prostitución.

El precario e incompleto andamiaje jurídico a disposición de la protección de los derechos de las mujeres adultas que obtienen ingresos a través del intercambio de sexo las sitúa, sin duda, en una condición de vulnerabilidad. Para algunas autoras, la vulnerabilidad deriva del hecho mismo de ser prostituidas, entendiendo la prostitución como una manifestación de la violencia de género ${ }^{8}$. Para otras, la aplicación de políticas prohibicionistas (aun en la versión encubierta que se incluye en las ordenanzas municipales) precariza y victimiza a las personas que desempeńan esta actividad'. Otras autoras, afirman que la situación de vulnerabilidad deriva de la ausencia de un cuadro normativo que proteja los "derechos laborales" y la seguridad o salud en el trabajo y que reconozca las prestaciones de seguridad social ${ }^{10}$.

Siendo cierto que el actual marco jurídico no protege a las mujeres que son prostituidas o toman la decisión de prostituirse, lo cuestionable es que el derecho del trabajo, el reconocimiento de la posibilidad de someter formalmente a un régimen de subordinación la venta de servicios sexuales y permitir el lucro ajeno por ellos, sea una solución efectiva y compatible con la protección de la dignidad de las personas.

He aquí el marco de un debate que debe tener como eje común la voluntad de superar la situación o situaciones de vulnerabilidad, actuando siempre con pleno respeto a la autonomía individual de las personas implicadas. El dilema, más allá de posicionamientos de carácter tradicionalista, conservador o moralista, sobre los que no es necesario invertir espacio, estriba en qué papel y qué resultados queremos atribuir a la actuación jurídico-laboral sobre el fenómeno de la prostitución. En otras palabras, debemos valorar si el derecho del trabajo es el instrumento adecuado para dar soluciones a la situación de las personas enmarcadas en la prostitución, entendiendo la misma como realidad compuesta por muchos ejes (la exclusión, la discriminación, la vulnerabilidad, la subalternidad, la dominación, el racismo...).

Para hacer esta valoración es preciso acometer dos operaciones, la primera orientada a recordar (brevemente) cuales son las funciones posibles, en el momento actual, del derecho del trabajo y

${ }^{6}$ SUÁREZ LLANOS, L. "Caracterización de las personas y grupos vulnerables", en PRESNO LINERA, M. Protección jurídica de las personas y grupos vulnerables, Oviedo, Universidad de Oviedo, 2013, pp. 35-93.

${ }^{7}$ Seńala de manera acertada Beatriz Gimeno que, en un contexto de neoliberalismo extremo como el actual, escoger ser prostituta es una decisión tan racional como otra. Sin embargo, apunta la autora que el concepto de "decisión" en el que se mueve la afirmación anterior es una concepción neoliberal, que en general afecta al conjunto de nuestra vida, con nuevas formas de alienación y explotación, en particular respecto de las mujeres del Sur. Vid. GIMENO, Beatriz, "La prostitución: aportaciones para un debate abierto". Revista trasversales, mayo 2008.

${ }^{8}$ GUTIÉRREZ GARCÍA, Andrea, DELGAdO ÁlVAREZ, Carmen, "Vulnerabilidad en Mujeres Prostituidas: Medidas de Protección Legal”, Ońati Socio-legal Series, v. 5, n. 2, 2015.

${ }_{9}^{9}$ VILLACAMPA, Carolina, TORRES, Núria, "Políticas criminalizadoras de la Prostitución en España. Efectos sobre las trabajadoras sexuales” RECPC 15-06, 2013. Disponible en: http://criminet.ugr.es/recpc/15/recpc15-06.pdf

${ }^{10}$ SUÁREZ LLANOS, L. "Caracterización de las personas y grupos vulnerables", en PRESNO LINERA, Miguel. Protección juridica de las personas y grupos vulnerables, Oviedo, Universidad de Oviedo, 2013, pp. 35-93. 
la segunda, que se acomete en el apartado siguiente, examinar los instrumentos jurídicos diseñados y propuestos para determinar su eficacia respecto de los resultados esperados.

\subsection{El derecho del trabajo y su (limitada) función tuitiva}

Sin ánimo de realizar aquí un recorrido por la evolución de las funciones de la regulación del derecho al trabajo, nos interesa analizar brevemente la cuestionada función tuitiva de la norma laboral a efectos de valorar si el derecho del trabajo es un instrumento posible y efectivo para incidir sobre la cuestión. En primer lugar, y como cuestión evidente, cabe recordar que la función tuitiva del derecho laboral se despliega dentro del ámbito de las relaciones de producción, es decir, en el marco de la relación entre capital y trabajo. Aun cuando las notas de dependencia y ajenidad se hayan difuminado y transformado, el trabajo por cuenta ajena conlleva el ejercicio del poder de dirección y su correlativo ius puniendi, difícil de regular en relación a la explotación sexual ajena. Planteemos la tesitura, por ejemplo, de establecer por escrito los límites de lo que la "trabajadora" debe o no hacer/aceptar y la dificultad de cohonestar esta operación de manera coherente con la dignidad humana dentro de la relación laboral. Todo ello sin mencionar la actual pseudo prohibición de lucrarse explotando la prostitución de otra persona (ex art. 187.1 del Código Penal), en cuya compleja redacción entraremos en el apartado siguiente.

El segundo elemento fundamental para valorar si el derecho del trabajo es un instrumento deseable y eficiente en esta realidad es, precisamente, el propio cuestionamiento de la función tuitiva del derecho del trabajo, que se ha demostrado tan criticada como contingente. Así, el anclaje constitucional de los artículos 1, 9.2 y 35, con la jurisprudencia constitucional que afirmaba el carácter tuitivo y compensador del derecho del trabajo ${ }^{11}$, no ha sido óbice para una deconstrucción de determinados institutos fundamentales que sostenían la función que comentamos. En este sentido es innegable que los márgenes de explotación de quien vende su fuerza de trabajo se ensanchan o estrechan en función de la relación de fuerzas existentes y que un simple vistazo al estado de reforma permanente de la década anterior nos evidencia que estos márgenes de explotación se han utilizado como un muelle para ajustar el precio de la fuerza de trabajo como mecanismo de gestión de las crisis económicofinancieras. La degradación de los derechos asociados al trabajo, a modo de devaluación interna, ha pasado por encima de la función tuitiva durante una década, que ahora se pretende contra-reformar.

Teniendo en cuenta los anchos márgenes de explotación y la contingencia de los diques de protección, es preceptivo preguntarse, y sobre eso volveremos en las conclusiones, si el derecho del trabajo es un instrumento útil o deseable para encajar, aceptándola como una relación de subordinación y dependencia, la explotación de la sexualidad ajena y la venta de la propia. En otras

\footnotetext{
${ }^{11}$ En las bien conocidas palabras del Tribunal Constitucional: “...la disparidad normativa se asienta sobre una desigualdad originaria entre trabajador y empresario que tiene su fundamento no sólo en la distinta condición económica de ambos sujetos, sino en su respectiva posición en la propia y especial relación jurídica que los vincula, que es de dependencia o subordinación de uno respecto del otro, y que posee una tradición que es innecesario concretar, en todo el amplio conjunto de consecuencias derivadas de dicha tradición... De todo ello deriva el específico carácter del Derecho laboral, en virtud del cual mediante la transformación de reglas indeterminadas que aparecen indudablemente ligadas a los principios de libertad e igualdad de las partes sobre los que se basa el Derecho de contratos, se constituye como un ordenamiento compensador e igualador en orden a la corrección, al menos parcialmente, de las desigualdades fundamentales..." (STC 3/1983, FJ.3. Vid también, recordando la finalidad tuitiva, la STC 22/1989, FJ. 2o: "La determinación del ámbito de aplicación subjetivo del Estatuto de los Trabajadores y, consecuentemente, la calificación de una relación contractual como laboral con la consiguiente inserción en un sector del ordenamiento regido por principios orientados a proteger a la parte más débil de tal relación diversificando así el contrato de trabajo de otras relaciones contractuales afines, civiles o mercantiles, ha dado lugar a supuestos singulares, en los que la no clara concurrencia de las notas de laboralidad del art. 1.1 ET, requerían una delimitación que, en ausencia de precepto expreso del legislador, se producía por vía de aplicación judicial y jurisprudencial a los casos concretos litigioso
} 
palabras, debemos evaluar la utilidad del derecho del trabajo, con su grado de precarización actual, como instrumento para reequilibrar en esta situación y como vía para mejorar la situación del sujeto vulnerable y de permitir su acceso en condiciones de igualdad al disfrute de bienes y derechos ${ }^{12}$.

Todo lo anterior no es obstáculo para reconocer a las personas protagonistas de esta realidad como sujetos con voz y exigencias, que deben ser incorporadas en las estrategias normativas, admitiendo el ámbito de libre decisión y autodeterminación de las personas adultas que, con todas la condiciones necesarias para superar la vulnerabilidad, decidan libremente vender sus servicios sexuales a cambio de una remuneración. En este caso, como veremos en los siguientes apartados, probablemente el derecho del trabajo tampoco sea el instrumento de regulación idóneo.

Con este escenario de partida, los siguientes apartados se dedican a analizar las distintas respuestas jurídicas posibles y su adecuación o no al objetivo de reducir la vulnerabilidad de los sujetos afectados y dar una respuesta a las personas que exigen una tutela jurídica, finalizando este texto con una propuesta de posible tercera vía.

\section{La prostitución como realidad y las reacciones jurídicas planteadas}

Como es bien sabido, la prostitución ha sido enfocada por el Derecho desde sus distintas ramas y, a efectos de este análisis, descartaremos la parte penal relativa a la trata para centrarnos en aquellas respuestas jurídicas enfocadas en la prohibición o la regulación de la prostitución ejercida con consentimiento entre adultos.

La primera consideración, recordada por Alemán Páez, es la complejidad de una realidad sobre la que se imbrican normas que responden a finalidades distintas en planos diversos ${ }^{13}$. Mientras que en el ámbito municipal se ha llegado a hablar de "modelo prohibicionista suave"14, en el ámbito estatal nos encontramos con una ausencia evidente de modelo político-normativo que se ha conjugado con una opción en materia penal cuasi-abolicionista (con muchos matices) cuyo eje es el artículo 187.1 del Código Penal ${ }^{15}$.

Cabe recordar que con la Ley Orgánica 11/2003 se introdujo en el Código Penal la figura del "proxenetismo no coercitivo", modificando la redacción del precepto (antiguo 188) para establecer

${ }^{12}$ SUÁREZ LLANOS, L. "Caracterización de las personas y grupos vulnerables", en PRESNO LINERA, Miguel. Protección juridica de las personas y grupos vulnerables, Oviedo, Universidad de Oviedo, 2013, pp. 35-93.

${ }^{13}$ De este autor, además de la citada, son importantes las siguientes aportaciones sobre el tema: ALEMÁN PÁEZ, Francisco, "Mercado del sexo vs. trabajo sexual/Abolicionismo vs. legalización de la prostitución: doble juego de binomios y propuestasreguladoras comparadas", RGLJ no 1, pp. 7-46, 2018; ALEMÁN PÁEZ, Francisco, "El trabajo sexual en la Ley Alemana reguladora de la Prostitución ("Prostituiertenschutzgesetz"). Bases teóricas y exegéticas de una isonomía crítica”, DRL, no 7, pp. 734-763, 2018.

${ }^{14}$ Con respecto a las ordenanzas municipales, Villacampa y Torres afirman que "por medio de estas ordenanzas municipales, Espańa está adoptando un sistema que podría tildarse de pseudo-prohibicionista o prohibicionista-suave, pues sanciona a las prostitutas, si bien con una sanción administrativa en lugar de con una sanción de carácter penal”. Continúan las autoras señalando que "la ofensiva contra la prostitución callejera -y ahora también de carretera- que comenzó hace menos de una década mediante la aprobación de las primeras ordenanzas cívicas ha sido incesantemente contestada por colectivos de trabajadores del sexo y de ONGs que realizan tareas asistenciales con éstos. Ellos ven en esta normativa una forma de criminalizar la pobreza, que precariza todavía más las condiciones de trabajo de las prostitutas callejeras". Vid. VILLACAMPA, Carolina, TORRES, Núria, "Políticas criminalizadoras de la Prostitución en España. Efectos sobre las trabajadoras sexuales" RECPC 15-06, 2013. Disponible en: http://criminet.ugr.es/ recpc/15/recpc15-06.pdf; Vid. también GONZÁLEZ GARCÍA, Sergio, "Prostitución y proxenetismo: una cuestión de Estado", Revista Aranzadi Doctrinal num. 10/2019.

${ }^{15}$ Señala Llobet que "en una escala de más a menos castigo penal se situarían, en un extremo, las posturas prohibicionistas (pena para los proxenetas no coercitivos, los clientes y las prostitutas); a continuación vendría el modelo abolicionista (pena para los proxenetas no coercitivos y los clientes); en tercer lugar, las posturas cuasi-abolicionistas (pena para los proxenetas no coercitivos, únicamente); y, finalmente, los modelos regulacionista y reglamentarista, cuya incidencia se produce en otras ramas del ordenamiento jurídico, aunque, por supuesto, tienen implicaciones penales en forma de no criminalización de cualquiera que, participando del fenómeno de la prostitución, no sea un proxeneta coercitivo". LLOBET, M., "Prostitución: ¿qué castigar? Trabajadoras, burdeles, rufianes y clientes”, Nuevo Foro Penal No. 92, enero-junio 2019 Universidad EAFIT. 
una sanción penal a toda explotación por terceros de la prostitución ajena, poniéndose el acento en el provecho económico. Sin embargo, el mismo precepto indica que "en todo caso, se entenderá que hay explotación cuando concurra alguna de las siguientes circunstancias: a) Que la víctima se encuentre en una situación de vulnerabilidad personal o económica. b) Que se le impongan para su ejercicio condiciones gravosas, desproporcionadas o abusivas".

Este artículo fue objeto de interpretación con la conocida STS de la Sala de lo Penal, 425/2009. En la misma, la Sala señaló que "la cuestión de la prostitución voluntaria en condiciones que no supongan coacción, engaño, violencia o sometimiento, bien por cuenta propia o dependiendo de un tercero que establece unas condiciones de trabajo que no conculquen los derechos de los trabajadores no puede solventarse con enfoques morales o concepciones ético-sociológicas, ya que afectan a aspectos de la voluntad que no pueden ser coartados por el derecho sin mayores matizaciones". En apoyo de esta opinión, se recoge la jurisprudencia del TJUE que ha considerado el trabajo sexual por cuenta propia amparado por la libertad de establecimiento y de prestación de servicios (art.49 TFUE $)^{16}$. Con este apoyo, la Sala consideró que la posibilidad de entender la prostitución como una actividad por cuenta propia, "no descarta sino que refuerza la tesis de que, al margen de razones de moralidad, pueda ser considerada como una actividad económica que si se presta en condiciones aceptables por el Estatuto de los Trabajadores" ${ }^{17}$.

Con estos mimbres jurídicos, prohibición (con muchos matices) del lucro por la explotación de la prostitución ajena y ausencia de regulación de cualquier otro tipo de intercambios sexuales a cambio de dinero, la responsabilidad tuitiva ha recaído en los jueces y tribunales, cuya actuación ha revelado una voluntad mayoritariamente protectora pero evidentemente insuficiente respecto de la generalidad del problema ${ }^{18}$. En este escenario de relativa anomia, la actuación de los operadores jurídicos se dirige a paliar las situaciones de vulnerabilidad con parches que, aun puntualmente útiles, no permiten superarlas.

A modo de resumen, cabe recordar que la aproximación jurisprudencial de principios de siglo se enfocó en una "finta" del artículo 187.1 del Código Penal (en su momento el 188) para reconocer la existencia de una relación laboral "por fuera" del elemento nuclear de la misma (el intercambio de sexo). De esta manera, con el objetivo de proteger a las trabajadoras, los tribunales realizaron lo que se conoce como "finta del alterne"19. La figura del alterne ha sido definida en reiterada jurisprudencia como aquella consistente "en que mujeres estimulen con su compañía y la mayor o menor exhibición de su físico, el consumo de bebidas por los clientes de un establecimiento donde aquéllas prestan el servicio a cambio de un porcentaje en el precio de la consumición, es aceptada hoy por la

\footnotetext{
${ }^{16}$ Sobre este tema, vid. GUAMÁN HERNÁNDEZ, Adoración, "La prostitución como actividad económica, la incidencia de la jurisprudencia del Tribunal de Justicia de las Comunidades Europeas sobre la cuestión”, Prostitución y trata: marco jurídico y régimen de derechos, SERRA CRISTÓBAL, Rosario, Tirant lo Blanch, Valencia, 2007

${ }^{17}$ Sobre esta cuestión vid. MAQUEDA ABREU, María Luisa, "Hacia una justicia de los derechos", Diario La Ley, 16. 3. 2010). También recuerda Agustí que, a partir de este pronunciamiento, otras sentencias han afirmado que dada una situación de prostitución por cuenta ajena no coercitiva, sólo cabria hablar del delito de "explotación laboral" cuando se detectan condiciones abusivas de trabajo (STS 651/2006, de 5 de junio) y se refiere a "explotación sexual lucrativa" cuando hay "grave riesgo para los derechos" (STS 152/2008, de 8 de abril). Vid. AGUSTÍ MARAGALL, Joan, "Razones para la laboralización de la -libre- Prestación de servicios de prostitución por cuenta ajena" IUSLabor $1 / 2015$.

${ }^{18}$ ALEMÁN PÁEZ, Francisco, "Prostitución masculina y trabajo sexual (STSJ de Cataluña, de 11 de noviembre de 2019): avances de una aporía litigiosa” Derecho de las Relaciones Laborales (en prensa)

${ }^{19}$ Respecto del "alterne" señala Fernando Fita que cabe la consideración del mismo como relación laboral cuanto dicha actividad "genera unos rendimientos económicos, previa la organización de capital y trabajo, que deben estar sometidos a las condiciones tributarias y laborales que protegen a los trabajadores y disciplinan los presupuestos mercantiles de toda actividad económica. Entre muchas sentencias recogidas por el autor vid. la STSJ de Castilla y León de 31 de marzo de 2005 (AS 2720). FITA ORTEGA, Fernando, "La prostitución: posible objeto de contrato de trabajo como una manifestación más del trabajo sexual", Revista de derecho social, No 47, 2009, pp. 91-108
} 
jurisprudencia como relación laboral"20. Se trata de una actividad laboral si se dan las notas de dependencia y ajenidad ${ }^{21}$, considerada como distinta a la prostitución ${ }^{22}$. Es más, "a esta consideración de actividad lícita y reconocimiento de laboralidad no se opone que el alterne pueda tener su fin en la prostitución, al distinguir ambas actividades y sin que ésta pueda descalificar aquélla”23.

La artificiosidad de la figura del alterne y su resultado final, el reconocimiento de la condición de trabajadoras subordinadas de las prostitutas sin que la protección laboral abarque el núcleo de la relación, se conjugaron con una negativa reiterada por parte del orden social de la jurisdicción a considerar la prostitución como una realidad incardinable en un contrato de trabajo. En este sentido señalaba Agustí como esos mismos pronunciamientos relativos al alterne incluían con carácter "obter dicta" una negativa categórica respecto de la inclusión de la prostitución en el ámbito del contrato de trabajo, entendiendo que un contrato para estos servicios con carácter de prestación subordinada tendría objeto y causa ilícitos, aún cuando sea por decisión voluntaria de la persona que ejerce la prostitución; además, esos mismos pronunciamientos señalaban que tal contrato sería en todo caso nulo por contravenir frontalmente diversos derechos fundamentales ${ }^{24}$. Así, más allá del código penal, la imposibilidad de considerarlo como una relación laboral se derivaría de las incompatibilidad absoluta entre las notas de ajenidad y dependencia con el proxenetismo y la libertad y la dignidad humanas.

Sin embargo, existen pronunciamientos que se han separado de manera total o parcial de este parecer.

Por un lado, la Sentencia del juzgado de lo social no 10 de Barcelona, de fecha 18.2.2013, aceptó la laboralidad de unas trabajadoras de un "centro de masajes eróticos" afirmando que "nos hallamos ante una relación de prostitución por cuenta ajena clara y diáfana, no enmascarada o interferida por una paralela o confluente relación de alterne”.

\footnotetext{
${ }^{20}$ La laboralidad del alterne fue tempranamente rechazada por el antiguo Tribunal Central de Trabajo (en sentencias de 13 de marzo de 1975 y de 1 de abril de 1978). No obstante, el Tribunal Supremo, en su sentencia de 3 de marzo de 1981, afirmó la posibilidad de que en el alterne se dieran las notas típicas de una relación de trabajo.

${ }^{21}$ Notas que ha resumido FITA en los siguientes puntos que las trabajadoras estén sometidas a un horario; que acudan diariamente al centro de trabajo; que ejerzan la actividad en las instalaciones del empresario, existiendo un control de la actividad desarrollada y siendo aquél quien determine el importe de las copas a las que les invitan los clientes y quien cobre las consumiciones, abonándosele posteriormente a la trabajadora la comisión devengada por su trabajo; que realicen su actividad en régimen de exclusividad; que empleen taquillas y vestuarios facilitados por el empresario; que perciban una retribución estable; que sean trasladadas al local por un vehículo propiedad de la empresa; que se les exija un determinado vestuario; que el empresario ostente poder disciplinario o sancionador sobre las trabajadoras; y que la trabajadora carezca de cualquier infraestructura empresarial propia. FITA ORTEGA, Fernando, "La prostitución: posible objeto de contrato de trabajo como una manifestación más del trabajo sexual", Revista de derecho social, No 47, 2009, pp. 91-108. También sobre esta cuestión vid. ARIAS DOMÍNGUEZ, Ángel., "Prostitución y derecho del trabajo jauténtica relación laboral?”, Aranzadi Social: Revista Doctrinal, Vol. 1, No. 17 (Feb), 2009, pags. 39-48; CONDE-PUMPIDO TOURÓN, Teresa, "Es conveniente regular el ejercicio de la prostitución”, en AGUSTÍ JULIÀ, Jordi., PUMAR BELTRÁN, Núria., El trabajo por cuenta ajena y sus fronteras, Bomarzo, Albacete, 2010; DESDENTADO BONETE, Aurelio, "Contrato de trabajo y prostitución: una reflexión sobre la sentencia de la Sala 2. a del Tribunal Supremo de 14 de abril de 2009”, Diario La Ley, No 7238, 2009; FERNÁNDEZ FERNÁNDEZ, Roberto, TASCÓN LÓPEZ, Rodrigo, ALVAREZ CUESTA, Henar, QUIRÓS HIDALGO, José Gustavo, "Sobre la posible regularización laboral de la prostitución: reflexiones para un debate", Estudios financieros. Revista de trabajo y seguridad social, No. 289, 2007, pp. 3-50; REY MARTÍNEZ, Fernando, MATA MARTÍN, Ricardo, SERRANO ARGÜELLO, Noemí, Prostitución y Derecho, Aranzadi, 2004.

${ }^{22}$ La SAN de 23 de diciembre de 2003 (AS 2003/3692), en el conocido caso Mesalina, señalaba que "nuestra jurisprudencia ha incluido en la relación laboral en el supuesto de concurrir la ajenidad y la dependencia organizativa a la prestación de servicios de "alterne" que aunque no identificable con la de prostitución, supone precisamente el límite prestacional con ésta; un límite fisiológico pues el favor sexual no puede ser objeto de subordinación empresarial y un límite jurídico entre el trabajador por cuenta ajena -relación de alterne- y el trabajador por cuenta propia --relación de prostitución-". Sobre esta sentencia vid. SÁNCHEZ TRIGUEROS, Carmen, "El Tribunal Supremo zanja el caso "Mesalina". Comentario a la STS de 27 de noviembre de 2004", AS vol. V (XIV) 2004.

${ }^{23}$ STSJ de Asturias de 25 octubre AS $2010 \backslash 2390$.

${ }^{24}$ Sobre esta sentencia vid. el comentario del propio magistrado: AGUSTÍ MARAGALL, Joan, "Razones para la laboralización de la -libre- Prestación de servicios de prostitución por cuenta ajena" IUSLabor 1/2015. Y el comentario de QUESADA SEGURA, Rosa "Por primera vez, la prostitución como objeto del contrato por cuenta ajena. Interpretación judicial de la protección de la igualdad de género", REDT nº.180, 2015.
} 
El magistrado concede que "hasta el momento, los juzgados y tribunales de lo social han negado categóricamente la posibilidad de que exista y pueda ser válido un contrato de trabajo que dé cobertura a las situaciones de explotación lucrativa de la prostitución, al considerar que para que el contrato de trabajo pueda reputarse válido es imprescindible que su objeto y causa sean lícitos, considerándose que la explotación sexual de una persona no reúne ni puede reunir esta condición, aunque el ejercicio de la prostitución sea una decisión voluntaria de la persona que la ejerce”.

Sin embargo, la sentencia determinó la laboralidad de la prestación apoyándose en dos elementos fundamentales: por un lado, la declaración de una trabajadora que, a pregunta del magistrado, confirmó que "ejerció la prostitución por cuenta ajena de forma libre, no coaccionada (más allá, obviamente, de la situación social y económica que puede haberla inducido al ejercicio de la prostitución), sin que ni ella, ni la Inspección de Trabajo, ni la TGSS, en su demanda de oficio, hayan puesto de manifiesto "condiciones abusivas de trabajo" o de "grave riesgo para los derechos". Por otro lado, la decisión se apoyó en la doctrina y en la Resolución del Parlamento Europeo, de 26 de febrero de 2014, sobre explotación sexual y prostitución y su impacto en la igualdad de género para acabar considerando que "precisamente por tratarse de una cuestión de género y por los derechos fundamentales que están implicados, considera este magistrado que en tanto el Estado Español -como ya han hecho diversos países comunitarios- no asuma el "modelo nórdico" de lucha contra la prostitución (recomendado en el apartado 29 de dicha resolución) no puede llegar a tal conclusión, por cuanto - paradójicamente- ello no haría más que agravar la situación, también desde la perspectiva de género, de las trabajadoras afectadas". Por todo lo anterior concluyó que "en el actual marco regulador de la prostitución (regulación administrativa y despenalización aplicativa), habiendo quedado plenamente acreditado que las trabajadoras ejercían libremente, sin coacción y de manera no forzada, la prestación de servicios de prostitución por cuenta de la empresaria demandada, bajo su dirección y dependencia, no son de apreciar motivos de ilicitud penal ni de lesión de derechos fundamentales individuales que impidan el reconocimiento de laboralidad".

En sentido contrario, cabe destacar los pronunciamientos que se han manifestado decididamente en contra de la posibilidad de incardinar la actividad de prostitución dentro del marco de un contrato de trabajo. En primer lugar, la bien conocida sentencia de la Audiencia Nacional relativa al sindicato OTRAS. En ella, la Audiencia concluyó que "No resulta posible con arreglo a nuestro derecho la celebración de contrato de trabajo cuyo objeto sea la prostitución por cuenta ajena, esto es, un contrato en virtud del cual el trabajador asuma la obligación de mantener las relaciones sexuales que le indique el empresario, con las personas que este determine a cambio de una remuneración, y el contrato que así se celebre debe reputarse nulo. Y ello, sin perjuicio de que el que se obligó con la condición de trabajador pueda reclamar frente al empresario los derechos que al efecto le reconoce el art. 9.2 E.T por los servicios prestados" 25.

Por último, reviste una especial importancia la sentencia del Tribunal Superior de Justicia de Barcelona $^{26}$, cuyo ponente fue el magistrado Carlos Hugo Preciado Domenech ${ }^{27}$. La virtud del pro-

\footnotetext{
${ }^{25}$ Continúa la Audiencia señalando que "Hemos de referir que si bien es cierto que existen resoluciones dictadas por Tribunales superiores de justicia dictadas en procedimientos de oficio instados por la autoridad laboral, en los que se ha admitido la condición de trabajadores por cuenta ajena de personas que ejercían la prostitución, lo determinante para el reconocimiento de tal condición, no ha sido nunca el ejercicio de la prostitución, antes al contrario, sino el ejercicio de una actividad por cuenta ajena lícita y perfectamente separable del ejercicio de la prostitución, actividad esta que se desarrolla por cuenta propia por los trabajadores de alterne, aun cuando se desarrolle en instalaciones propias del empleador destinadas a la habitación del trabajador".

${ }^{26}$ STSJ de Cataluña de 11/11/2019 (Ro 8972/2019)

${ }^{27}$ Es interesante recordar que entre la obra del Magistrado destaca su interesante contribución al debate sobre los derechos fundamentales en el contrato de trabajo, en su obra PRECIADO DOMENECH, Carlos Hugo, Teoría general de los derechos fundamentales en el contrato de trabajo, Aranzadi, Madrid, 2017. Sobre esta sentencia es imprescindible la lectura de: ALEMÁN PÁEZ, Francisco, "Prostitución masculina y trabajo sexual (STSJ de Cataluña, de 11 de noviembre de 2019): avances de una aporía litigiosa" Derecho de las Relaciones Laborales (en prensa)
} 
nunciamiento es su ubicación en la difícil posición de garantizar los derechos humanos y poner la resolución de la situación de vulnerabilidad en el centro, sin utilizar para ello ni la finta del alterne (se trata de un caso radicado en un centro de "masajes") ni el encuadramiento de la prostitución en un marco de subordinación y dependencia.

Para ello, la sentencia realiza una extensa aproximación por la normativa internacional y estatal y recuerda que, como señalamos anteriormente, "el CP sanciona la explotación de la prostitución ajena y no la mera obtención de lucro con la misma, de forma que se exige la detracción de los ingresos de la persona prostituida en una parte no proporcionada-abusiva- por ofrecerle alojamiento, lugar de encuentro con los clientes u otros servicios, en suma cuando no haya un intercambio libre de trabajo sexual por precio".

Con esta afirmación prescinde del tipo penal para centrarse en la prestación en concreto. Al estudiarla a la luz de un amplio análisis jurisprudencial, la sentencia concluye que nos hallamos ante un supuesto de prostitución voluntaria por cuenta ajena, enmarcada en las notas de dependencia y subordinación propias de toda relación laboral. Sin embargo, "el objeto del contrato es ilícito, ( art.1261 y 1271-1273 CC), no porque el trabajo sexual deba considerarse "contrario a la moral" ni porque dicho trabajo deba ser objeto de estigma o intrínsecamente indigno, sino porque su prestación en régimen de subordinación, con sujeción a órdenes, instrucciones sobre el con quién, cómo, cuándo y dónde de dicha prestación, sujetando a la potestad disciplinaria la desobediencia de las órdenes del empresario ( art. 5c ) y 20 ET ), resulta contraria a la dignidad humana (art.10.1 CE)".

Recuerda la sentencia que en el ámbito de la UE, el trabajo sexual por cuenta propia se consideró amparado por la libertad de establecimiento y de prestación de servicios (art.49 TFUE) y que en nuestra realidad ha sido contemplado como posible dentro del marco de la libre elección de profesión u oficio ${ }^{28}$, por lo que no puede considerarse como "indigno". Lo que provoca la colisión con los derechos fundamentales por tanto no es el trabajo en sí mismo sino su prestación bajo régimen de subordinación y disciplina empresarial. Esta circunstancia, según afirma la sentencia "sí que cosifica a la persona en uno de sus más íntimos aspectos de la personalidad, la libertad sexual. En el caso de la libertad sexual y la intimidad, el esquema de subordinación -en sí mismo- afecta al contenido esencial de ambos derechos. Que alguien tenga derecho a controlar, sancionar y ordenar sobre el contenido de la libertad sexual e intimidad supone una afectación a su contenido esencial (art. 53.1 CE), convierte en irreconocibles tales derechos, y dejan de proteger los intereses fundamentales conforme al concepto de contenido esencial consagrado por la STC 11/1981, de 8 de abril (f.8)".

Siendo el contrato totalmente nulo, no cabe la acción de despido pero sí, y aquí da otro giro interesante la sentencia, cabría una acción para exigir la remuneración correspondiente (art.9.2 ET) y la acción de tutela de los derechos fundamentales vulnerados, particularmente la dignidad la libertad sexual, que forma parte del derecho a la intimidad (art.18 CE).

La disparidad de pronunciamientos sobre un fenómeno similar ratifica lo seńalado al principio de este apartado respecto de la labor del poder judicial, que debe solventar no solo un vacío jurídico sino claras indeterminaciones, cuando no contradicciones, en la política normativa que son, sin duda, fruto y reflejo de la enconada discusión respecto a este fenómeno. Las dos posturas que referimos en la introducción, abolicionismo y movimiento "pro-derechos" se presentan como irreconciliables mientras ni los operadores jurídicos, ni la doctrina, enredados en este debate, son

\footnotetext{
${ }^{28}$ En este sentido vid: LÓPEZ I MORA, Federico, "Prostitución y estatuto profesional", Prostitución y trata: marco jurídico y régimen de derechos, SERRA CRISTÓBAL, Rosario, Tirant lo Blanch, Valencia, 2007, pp. 157-202; POYATOS Y MATAS, Gloria, La prostitución como trabajo autónomo, en AGUSTÍ JULIÀ, Jordi, PUMAR BELTRÁN, Núria, El trabajo por cuenta ajena y sus fronteras, Bomarzo, Albacete, 2010;
} 
capaces de dar una respuesta que, hasta el momento, permita esbozar una solución basada en la superación de la situación de vulnerabilidad de las mujeres que transitan la prostitución.

$\mathrm{Ni}$ el abolicionismo coloca (aquí y ahora) a las prostitutas o prostituídas en una situación que les permita mejorar sus condiciones vitales ni el reconocimiento de una relación laboral subordinada parece idóneo para una prestación que mal resistiría el ejercicio de los poderes de dirección del empresario. En esta tesitura, como señalamos al principio de estas páginas, se plantea como necesario pensar en un punto intermedio.

\section{No-vulnerables: una solución inmediata para caminar hacia un futuro libre de prostitución (y de patriarcado)}

Entre el abolicionismo mixto o moderado y el enfoque pro-derechos podría construirse una propuesta centrada en la superación de las condiciones de vulnerabilidad que como se señaló en las primeras páginas derivan de manera conjunta del género y por tanto de la dominación patriarcal como base, pero también de la violencia y de la desprotección jurídico-normativa de las personas que ejercen la prostitución.

Este punto intermedio exige un acuerdo alrededor de varias premisas. La primera, probablemente, es el reconocimiento. El reconocimiento de las mujeres que se consideran prostitutas o de las que se sienten prostituidas y de las necesidades que ambos grupos expresan, intentando construir una respuesta vinculada a las luchas sociales que las representan. En este sentido, es útil recordar que el Derecho, habitual cómplice de la sedimentación de las desigualdades, también puede (debe) servir como instrumento de efectiva alteración de las prácticas reales vigentes, como un medio o una técnica entre otras muchas, para garantizar el resultado de las luchas e intereses colectivos hacia la justicia social ${ }^{29}$. Se requiere por tanto, una respuesta situada, alejada del maniqueísmo que permea intensamente el debate y que no permite un diálogo sosegado para centrarse en lo importante, que es la situación inmediata y futura del amplio conjunto de mujeres.

La segunda premisa es el aprendizaje de los errores y el conocimiento de los límites del derecho del trabajo. La experiencia nos demuestra que encajar en un molde jurídico rígido una realidad que no se ajusta conlleva la permanencia de situaciones que por acción u omisión se queda "fuera" (véase la deriva de la relación laboral especial de hogar). Pero además, sabemos bien que cubrir una realidad precaria con una solución laboral precaria tampoco es la solución ¿acaso vamos a permitir las ETT y los contratos por horas para la prostitución?; y, por supuesto, seguir pensando en que debemos anudar los derechos de ciudadanía, protección social, sanidad y en general acción estatal para una vida digna al empleo formal es, en estos momentos, un completo error.

La solución, y más tras la experiencia de la COVID-19, debería recaer en una estrategia mixta. Por un lado, el refuerzo de la universalidad de los derechos sociales, que permitan superar las desigualdades de género y las situaciones de carencia y falta de recursos. Las aportaciones estatales en forma de rentas de ciudanía son, sin duda, uno de los instrumentos fundamentales para la superación de un amplio conjunto de situaciones de vulnerabildiad. Si algo nos ha enseñado la llegada de la COVID-19, es que anudar las prestaciones sociales a la desvinculación de un empleo formal no permite cubrir todas las situaciones de vulnerabilidad. En este momento, se asienta la consciencia (y se confirma la posibilidad) de implementar una red de apoyo público con tendencia a la universalidad que trascienda la relación con el trabajo y permita sostener a las personas. En este sentido, las propuestas de renta básica, sea en su diseño original sea con algunas modulaciones, se

${ }^{29}$ Herrera Flores, Joaquín La reinvención de los Derechos Humanos, Sevilla: Atrapasueños, 2008 
presentan como un paso necesario para conseguir superar la proliferación de situaciones de vulnerabilidad a las que nos enfrentamos ${ }^{30}$.

Por otro lado, es igualmente necesario el apoyo a las estructuras que las prostitutas decidan impulsar para organizar su trabajo y su relación con los clientes, sin necesidad de usar para ello el trabajo asalariado. Otras figuras que evitan el vínculo de subordinación pero refuerzan el de colectividad (las cooperativas por ejemplo) podrían resultar más adecuadas para permitir el desarrollo de esta actividad a quien se libremente y así lo decida. De igual manera, el apoyo (asesoramiento en materia de formalización de la prestación, prevención de riesgos, etc) para las que decidan establecerse como autónomas también podría impulsar una dignificación de la vida de quienes, teniendo cubiertas las necesidades vitales mediante los servicios públicos de calidad y las aportaciones estatales necesarias, decidan ejercer la prostitución.

Una vez conseguido el primer paso, dignificar la vida y responder a las necesidades, deberíamos sin duda abordar un debate sereno acerca de cómo caminar hacia el fin de la prostitución, ya que nunca debemos perder de vista que, en el fondo, la prostitución contamina la lucha por la igualdad en tanto refuerza los roles de género y la dominación masculina ${ }^{31}$.

\footnotetext{
${ }^{30}$ Sobre el tema, y entre las innumerables aportaciones, vid. BOLLAÍN, Julen, RAVENTÓS, Daniel, "La Renta Básica Incondicional ante las limitaciones de las Rentas Mínimas”, Lan harremanak: Revista de relaciones laborales, № 40, 2018.

${ }^{31}$ Vid. GIMENO, Beatriz, "Prostitución: cuestión de derechos y privilegios", en Ctxt, No 239, 2019. Disponible en: https:// ctxt.es/es/20190918/Firmas/28489/prostitucion-institucion-patriarcal-desigualdad-beatriz-gimeno.htm
} 